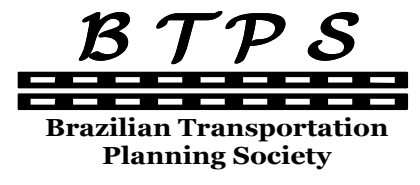

Journal of Transport Literature

Vol. 7, n. 2, pp. 352-372, Apr. 2013

Research Directory
JTL | RELIT

www.transport-literature.org ISSN 2238-1031

\title{
Risk assessment in airlines stocks market
}

[Avaliação do risco no mercado de ações de companhias aéreas]

\author{
Renato Cesar Sato*
}

Universidade Federal de São Paulo, Brazil

Submitted 1 Jul 2012; received in revised form 19 Aug 2012; accepted 26 Aug 2012

\begin{abstract}
In this paper we compared the results between stock portfolios of North American and European airlines. The model accesses the market risk using Value-at-Risk approach in both portfolios over one month period. The analysis was performed through the use of GARCH-EVT methods and Student's-t Copula with a Monte Carlo Simulation. The assets in the financial market usually present heavy tails in their probability distributions, so, a process capable to deal with this issue is crucial to measure the risk of loss. We analyzed the period from mid-2007 to mid-2012 to compose comparison between these two portfolios. The financial crisis of 2008 had a great impact in the North America market in relative to the European market. The central role of transport in the economy makes studies dealing with investment risk measure in this sector crucial for the industrial development. The volatility of risk in the airline market happens by internal and external motives and the methodological development of financial tools can offer an important contribution due the investment flux dependency.
\end{abstract}

Key words: value-at-risk, garch, aviation, stocks, market risk.

\section{Resumo}

Neste trabalho foram comparados os resultados entre carteiras de ações de companhias aéreas Norte-americanas e Europeia. 0 modelo avalia o risco de mercado utilizando a abordagem do Value-at-Risk em ambas às carteiras ao longo de um mês. A análise foi realizada através do uso dos métodos GARCH-EVT e t-Student Copula com simulação de Monte Carlo. Os ativos do mercado financeiro costumam apresentar caudas pesadas em suas distribuições probabilísticas, portanto, um processo de modelagem capaz de lidar com esse aspecto é fundamental para mensurar o risco de perda dos investimentos. Foi analisado o período de meados de 2007 até meados de 2012 para compor uma comparação entre as duas carteiras. A crise financeira deflagrada em 2008 teve um maior impacto nas ações do mercado Norte Americano quando em relação ao mercado Europeu. A participação central dos transportes na economia faz com que estudos de avaliação do risco de investimento nesse setor sejam cruciais no processo de desenvolvimento industrial. A volatilidade do risco nesse mercado ocorre tanto por motivos internos e externos ao setor da aviação e o aprimoramento metodológico das ferramentas financeiras pode oferecer uma importante contribuição devido a dependência dos fluxos de investimentos.

Palavras-Chave: valor em risco, garch, aviação, ações, risco de mercado.

*Email: rcsato@unifesp.br.

\section{Recommended Citation}

Sato, R. C. (2013) Risk assessment in airlines stocks market. Journal of Transport Literature, vol. 7, n. 2, pp. 352-372.

- JTL/RELIT is a fully electronic, peer-reviewed, open access, international journal focused on emerging transport markets and published by BPTS - Brazilian Transport Planning Society. Website www.transport-literature.org. ISSN 2238-1031. 


\section{Introduction}

This paper presents an analysis of potential loss between two portfolios of stocks from aviation companies from the United States and Europe using Value-at-Risk (VaR) framework. The VaR method measures risk of loss with a given degree of confidence on a specific portfolio in a period of time. After the mid-1990s, VaR practically became the standard on risk assessment in many financial institutes. More recently the estimating tail risk using extreme value theory (EVT) became an important approach due to the possibility of capturing with precision the outer limits of the returns. Hence, it is far superior to the normal distribution curve which has too thin of tails to capture the market overreactions commonly found in financial markets. We made use of the EVT-VaR approach to analyze the selected portfolios risks.

The financial overreaction happen more frequently than we expect and sometimes with a huge impact. The first financial crisis of this century was the financial meltdown in 2008. It was marked by the collapse of large financial institutions and bailout of banks by governments and also an extreme downturn in stock markets with a rigorous impact in airlines stock value. The United States stock market started a downturn in October of 2008 and in March of 2009 the Dow Jones Industrial Average index felt more the half. As consequence the European market was contagion by this downturn (Horta, Mendes and Vieira, 2010) like many other markets.

The value stocks are also influenced by volatility due to the industrial organization. From 1977 to 1992 , low profits and many structural changes in the sector promoted the feeling of high risk investments in companies in the aviation industry. The gross revenues of the airlines were about \$ 2 trillion with an operating cost of about \$ 1.96 trillion (Dempsey, 1995) resulting low profits. It is important to mention that it was a turbulent time for the aviation sector, especially in the United States with the deregulation in 1978. Minimal government intervention in the sector to control the fares and routes simultaneously with entry of smaller companies encouraged main airlines to seek an expansion of investment to maintain their competitiveness. This did not mean that the sector is in a downward spiral, but a great adjustment permeated with high financial volatility. Some companies in the United States earned profits in 2010 such as the net income of $\$ 158$ million in the last quarter of 2010 at 
Delta Airlines (Delta Airlines, 2011) and \$ 131 million in the same period by Southwest Airlines (Southwest Airlines, 2011).

Airlines play an essential role in the context of travel and tourism with approximately 2.8 billion transported passengers globally in 2011. This industry also employs about 56 million people in the tourism and aviation, and about 8.36 million are directly employed in the aviation industry (ATAG, 2012). This makes their participation in the financial market substantial, with shares of leading companies traded daily on stock exchanges worldwide. However, the theme of financial economics on aviation are still little explored in literature both from the standpoint of analysis and methodological framework.

Despite the revitalization and profits of some companies recently, many challenges still are unanswered with the prospect of increase in the price of petroleum and the competitiveness imposed by the low-cost carriers (LCC). The market perception can help understand the industry and its economic and industrial context. Thus, understanding the volatility and risk associated with the airlines is an important tool for evaluating this industry's developments and its prospects in recent years. Another advantage is the association with the cost of capital for investments and risk arising from the volatility of stock prices. A greater price volatility of companies suggests higher cost of capital (Minton and Schrand, 1999). Financial markets have an inherently high volatility and when analyzed from the viewpoint of the value of the shares of airlines it may be even greater. Thus, the analysis focused on the risk arising from the perception of the market value companies offering an important contribution to studies of civil aviation. Another advantage is the possibility to compare the risk of airlines companies in different geographical regions which helps understanding regional marketing aspects. Despite the civil aviation market is of global market, reflections and economic structures of the companies still meet certain aspects imposed by their home countries or regions where it operates. In this turbulent time of financial instability we may pose a question if the volatility in the stock values of United States airlines is greater than the in Europe. This stock volatility happens to be an essential question for the transportation literature due to the size of this industry in the economies.

A form of evaluating the possibility of risk is to estimate the possibility of maximum loss which an investor may have in investing in the airline sector. The Value at Risk is a financial analysis tool able to estimate the maximum loss on an investment in a given period. The 
Value at Risk (VaR) models seeks to estimate the distribution of returns of lower tails of a portfolio. There is, however, the challenge of implementing a model based on historical data that captures the proper distribution of the tails of the probabilistic distribution (Carol Alexander, 2008). In this paper we deal with this challenge using the Extreme Value Theory (EVT) and Copula fitting before the VaR. To make this assessment two portifolios were created, one for United States companies and other for European companies. Both portfolios were analyzed separated to access their VaR value in $90 \%, 95 \%$ and $99 \%$ confidence intervals.

We start by presenting the technical aspects about portfolio modeling. In this section we present the main theories used to process the data, the ARMA-GARCH model, Extreme Value Theory (EVT), Copulas and Value-at-Risk. These are extense themes, making it impossible to cover and review all aspects in this paper. The following section presents the Model Simulation, this section is separeted in two main subsections: data and analysis. In the data subsection the information about the data souces and nature are presented. In the analysis section the estimation of extreme distribution t-copula estimation and simulation process are presented. The result analysis section shows the main findings of this research and limitations, and finally the conclusion gives an overview and sugestion for further research.

\section{Modeling Portfolio}

The high volatility of the portfolio based on United States airlines when compared with the Standard \& Poor 500 (S\&P500) market index suggests more extreme reactions from the market regarding these companies (Figure 1). The reasons for this volatility may be due to factors such as increased fuel prices or new market regulations redefining aspects of industrial organizations in the sector. These issues are inherent in the internal structure in which the market can offer negative responses from the perspective of a decrease in the competitiveness of a particular company or even the loss of profitability of the airline industry. The problems of low profitability in the aviation sector distances investors or at least make them more sensitive to potential losses on their investments. 


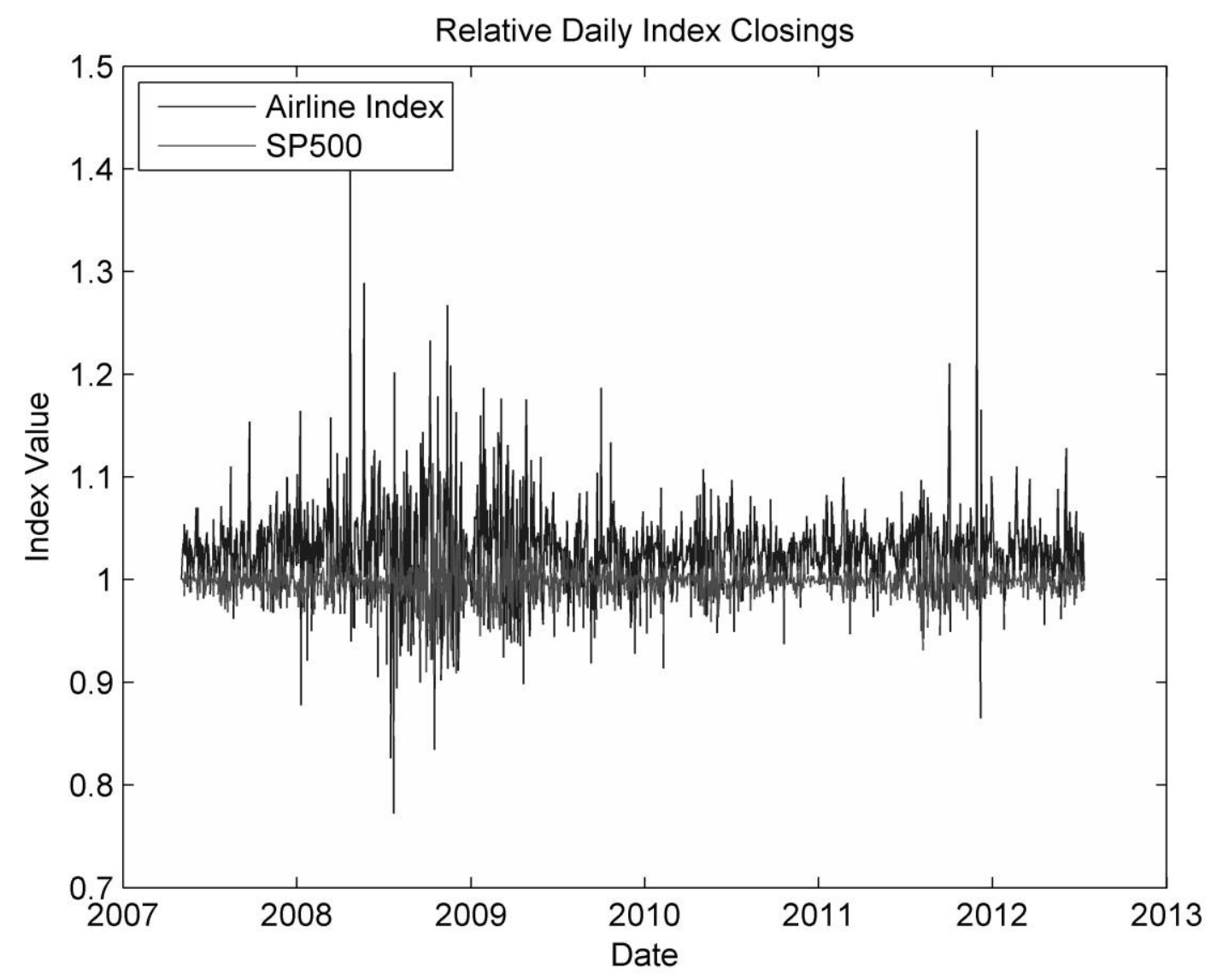

Figure 1 - Comparison of volatility between stock returns of U.S. Airlines with the S\&P500 Index.

The high volatility of the stock of companies in the United States airline portfolio when compared with the S\&P500 market index suggests more extreme reactions from the market for these companies.

To deal with the high volatility in the airline stocks the simple VaR model is not suitable. To supress this limitation we will make use of the following models presented in this section. First we present the ARMA-GARCH model which are able to capture the volatility clustering as may be observed in Figure 1. Then we present the Extreme Value Theory as an important tool to estimation in the distribution tails. This is especially important in financial data which frequently has heavier tails in the distribution. Following, we introduce the Copula theory which plays an important role to capture asymmetric tail dependence, and finally the Valueat-Risk method to evaluate the risk of loss in on portfolio. 


\subsection{The ARMA-GARCH Models}

The matrix of covariance of estimates in the generalized autoregressive conditional heteroscedasticity $(\mathrm{GARCH})$ model is the focus of risk management systems using historical simulations or Monte Carlo Value at Risk (VaR). This is due to the model's ability to incorporate the effects of clusters of volatility in the returns portfolio analyzed (Alexander, 2010).

A autoregressive--moving-average model (ARMA) (p,q) model may be described as

$$
y_{t}=\mu+\sum_{i=1}^{p} \phi_{i} y_{t-1}+\sum_{j=1}^{q} \xi_{j} \varepsilon_{t-j}+\varepsilon_{t}
$$

Where $\varepsilon_{t}$ is independent and identically distributed with zero mean and variance $\sigma^{2}$. The ARMA models are used to capture the serial dependence. However, the conditional homoscedasticity assumption is restrictive in the financial markets permeated by clusters of volatility. The GARCH model is an extension of ARMA assuming $\varepsilon_{t}=z_{t} h_{t}$, with $z_{t}$ independent and identically distributed (i.i.d.) and $z_{t} h_{t}$ stochastically independent. The GARCH, however, are able to obtain the volatile clusters of financial data and excess kurtosis series (Nystrom and Skoglund, 2002b)

$$
k_{4}=\frac{E \varepsilon_{t}^{4}}{\left(E \varepsilon_{t}^{2}\right)^{2}}=v_{4} \frac{E h_{t}^{4}}{\left(E h_{t}^{2}\right)} \geq v_{4}
$$

Where $v_{4}$ is a $z_{t}$ kurtosis. One feature of the unconditional distribution is little variance in the center of the middle and some great variance in the tails of the distribution. The $\operatorname{GARCH}(1,1)$ is the conditional variance is described as:

$$
h_{t}^{2}=a_{0}+a_{1} \varepsilon_{t-1}^{2}+b h_{t-1}^{2}=a_{0}+\left(a_{1}+b\right) h_{t-1}^{2}+a_{1}\left(\varepsilon_{t-1}^{2}-h_{t-1}^{2}\right)
$$

This GARCH (1.1) described in terms of square errors may be described as $\varepsilon_{t}^{2}=a_{0}+$ $\left(a_{1}+b\right) \varepsilon_{t-1}^{2}-b\left(\varepsilon_{t-1}^{2}-h_{t-1}^{2}\right)+\left(\varepsilon_{t}^{2}-h_{t}^{2}\right)$, where $\left(\varepsilon_{t}^{2}-h_{t}^{2}\right)$ has conditional expectation equal to zero in the past information. In this paper the GARCH $(1,1)$ has the symmetry of shocks in volatility (Nystrom and Skoglund, 2002b). 
The GJR-GARCH (Glosten, Jagannathan and Runkle, 1993) is an evolution to the model proposed by (Engle, Ng and Rothschild, 1990) and is capable of capturing the effects where negative shocks have a major impact in volatility than positive shocks (Alexander, 2010).

$$
\sigma_{t}^{2}=\omega+\alpha \varepsilon_{t-1}^{2}+\lambda 1_{\left\{\varepsilon_{t-1}<0\right\}} \varepsilon_{t-1}^{2}+\beta \sigma_{t-1}^{2}
$$

Where the function $1_{\left\{\varepsilon_{t-1}<0\right\}}=1$ se $\varepsilon_{t}<0$ and the contrary 0 .

\subsection{Extreme Value Theory}

Extreme Value Theory may be used to obtain information of the tails for estimation of the distribution of return and makes $\mathrm{VaR}$ attractive for we are interested in the risk associated with these tails (Longin, 1996); (Pictet, Dacorogna and Müller, 1998); (Bali and Neftci, 2003). The EVT considers that the data are independently and identically distributed (i.i.d.), which is not true for financial assets. To deal with this limitation (A.J. McNeil and R. Frey, 2000) first proposed the use of GARCH in asset returns and the application of EVT to the residuals from the GARCH. This combination enables you to capture the conditional heteroscedasticity of the data through GARCH structure and model the behavior of heavy tails through EVT (Bali and Neftci, 2003), (Byström, 2005), (Fernandez, 2005), (Fong Chan and Gray, 2006).

EVT relates to a class of distributions which are derived from extreme values of a sample. Despite the possibility of modeling the entire distribution of random variables, this approach is generally used to quantify the probability of extreme losses (Alexander, 2008). The Generalized Pareto Distribution (GPD) is applied to a tail specific excess measuring under a certain predefined threshold (Alexander, 2008). This case uses the model-over-threshold peaks in the excess loss on a predefined measured threshold $(u)$.

$$
G_{u}(x)=P(X-u<x \mid X>u)=\frac{F(x+u)-F(u)}{1-F(u)}
$$

The GPD class is given as:

$$
G_{u}(x)=\left\{\begin{array}{cc}
1-\exp \left(-\beta^{-1} x\right), & \xi=0 \\
1-\left(1+\beta^{-1} \xi x\right)^{-\xi^{-1}}, & \xi \neq 0
\end{array}\right.
$$


Where $\beta$ is the parameter of the scale and $\xi$ is the tail index. The increase of the tail index leads to the increase of the tail weight. The excess of average loss under the $u$ threshold is given as $e(u)=E(X-u \mid X>u)$. The expected tail loss - ETL - is the average of all losses that exceed the VaR. The ETL is also called VaR conditional and it is used as an internal VaR measuring instrument.

$$
E T L=V a R+e(V a R)
$$

To calculate the ETL from historical data it is possible to estimate the process of loss of the $\mathrm{VaR}$ and also the $\beta$ and $\xi$ of the GPD kind of function to calculate $e(u)=\frac{\beta+\xi u}{1-\xi}$ with $u=$ VaR.

\subsection{Copulas}

The risk in a portfolio of assets is the uncertainty present in the distribution of returns. The use of copulas enables to overcome the limitation imposed by the correlation in the return on assets should be i.i.d. and also an elliptical shape in the distribution of the variables. Thus the copula is a function that connects two or more marginal distributions in the form of a distribution joint better than in the multivariate distribution ellipses. The process of the joint distribution specification may occur in two stages, first to the specific type of normal distribution, and then the distribution copula. The theory of copulas began with the seminal work (Sklar, 1959) and from the 70's gained strength for use in data modeling.

The t-Student copula is implicitly derived from a multivariate distribution function and can be defined by (Alexander, 2008):

$$
C_{v}\left(u_{1}, \ldots, u_{n} ; \boldsymbol{\Sigma}\right)=\boldsymbol{t}_{v}\left(t_{v}^{-1}\left(u_{1}\right), \ldots, t_{v}^{-1}\left(u_{n}\right)\right)
$$

Where $\boldsymbol{t}_{\boldsymbol{v}}$ and $t_{v}$ represents the functions of t-Student multivariate and univariate distribution with $v$ degrees of freedom and $\boldsymbol{\Sigma}$ the correlation matrix. The multivariate function of the tStudent density may be described as:

$$
f(x)=k|\boldsymbol{\Sigma}|^{-1 / 2}\left(1+v^{-1} \mathbf{x}^{\prime \mathbf{\Sigma}^{-1}} \mathbf{x}\right)^{-(v+n) / 2}
$$


Where $|\boldsymbol{\Sigma}|$ represents the determinate correlation matrix and $\mathrm{k}$ is defined as:

$$
k=\Gamma\left(\frac{v}{2}\right)^{-1} \Gamma\left(\frac{v+n}{2}\right)(v \pi)^{-n / 2}
$$

The multivariate distribution of the t-Student copula may be described as (Alexander, 2010; Bouyé, Durrleman, Nikeghbali, Riboulet and Roncalli, 2000):

$$
C_{v}\left(u_{1}, \ldots, u_{n} ; \boldsymbol{\Sigma}\right)=\int_{0}^{t_{v}^{-1}\left(u_{n}\right)} \ldots \int_{0}^{t_{v}^{-1}\left(u_{1}\right)} k|\boldsymbol{\Sigma}|^{-1 / 2}\left(1+v^{-1} \mathbf{x}^{\prime \Sigma^{-1}} \mathbf{x}\right)^{-(v+n) / 2} d x_{1} \ldots d x_{n}
$$

The differentiating enables the densities t-Student copulas as:

$$
C_{v}\left(u_{1}, \ldots, u_{n} ; \boldsymbol{\Sigma}\right)=K|\boldsymbol{\Sigma}|^{-1 / 2}\left(1+v^{-1} \xi^{\prime} \boldsymbol{\Sigma}^{-1} \xi\right)^{-(v+n) / 2} \prod_{i=1}^{n}\left(1+v^{-1} \xi_{i}^{2}\right)^{-(v+1) / 2}
$$

Where $\xi=\left(t_{v}^{-1}\left(u_{1}\right), \ldots, t_{v}^{-1}\left(u_{n}\right)\right)$ is the vector of achievements in the variables t-Student (Alexander, 2010).

\subsection{Value-at-Risk}

In the past years the models using Value-at-Risk $(\mathrm{VaR})$ in adverse condition won a significant importance in the financial field. The VaR measures the maximum expected loss in a determinate period of time given a level of significance. A portfolio that has a VaR of US\$100 in $10 \%$ means that only ten in 100 events a loss greater than US\$100 may occur. Part of the VaR popularity is because of its simplicity to communicate loss risk (Alexander, 2009). However, this simplicity carries the implicit limitation that asset returns are normally distributed. This limitation is especially important in financial assets where there is an excess kurtosis and skewness in asset returns especially in terms of loss. The possibility of using Extreme Value Theory (EVT) for information to estimate the tails of the distribution of returns is attractive because of $\mathrm{VaR}$ are interested in risk associated with these tails (Longin, 1996); (Pictet et al., 1998); (Gencay and Selcuk, 2004) (Brooks, Clare, Dalle Molle and Persand, 2005). EVT believes that the data are independently and identically distributed, which is not true for financial assets. To deal with this limitation (Alexander J. McNeil and Rüdiger Frey, 2000) first proposed the use of GARCH in returns on assets and the application 
of EVT to the residuals from the GARCH. This combination allows capture the conditional heteroscedasticity of the data through GARCH and formant modeling the behavior of heavy tails through the EVT (Bali and Neftci, 2003), (Fernandez, 2005).

\section{Model Simulation}

The process of simulation model to estimate the difference in risk between companies of the United States and Europe resulting from the volatility of the closing price of the shares was based on the methodological framework presented in Figure 2.

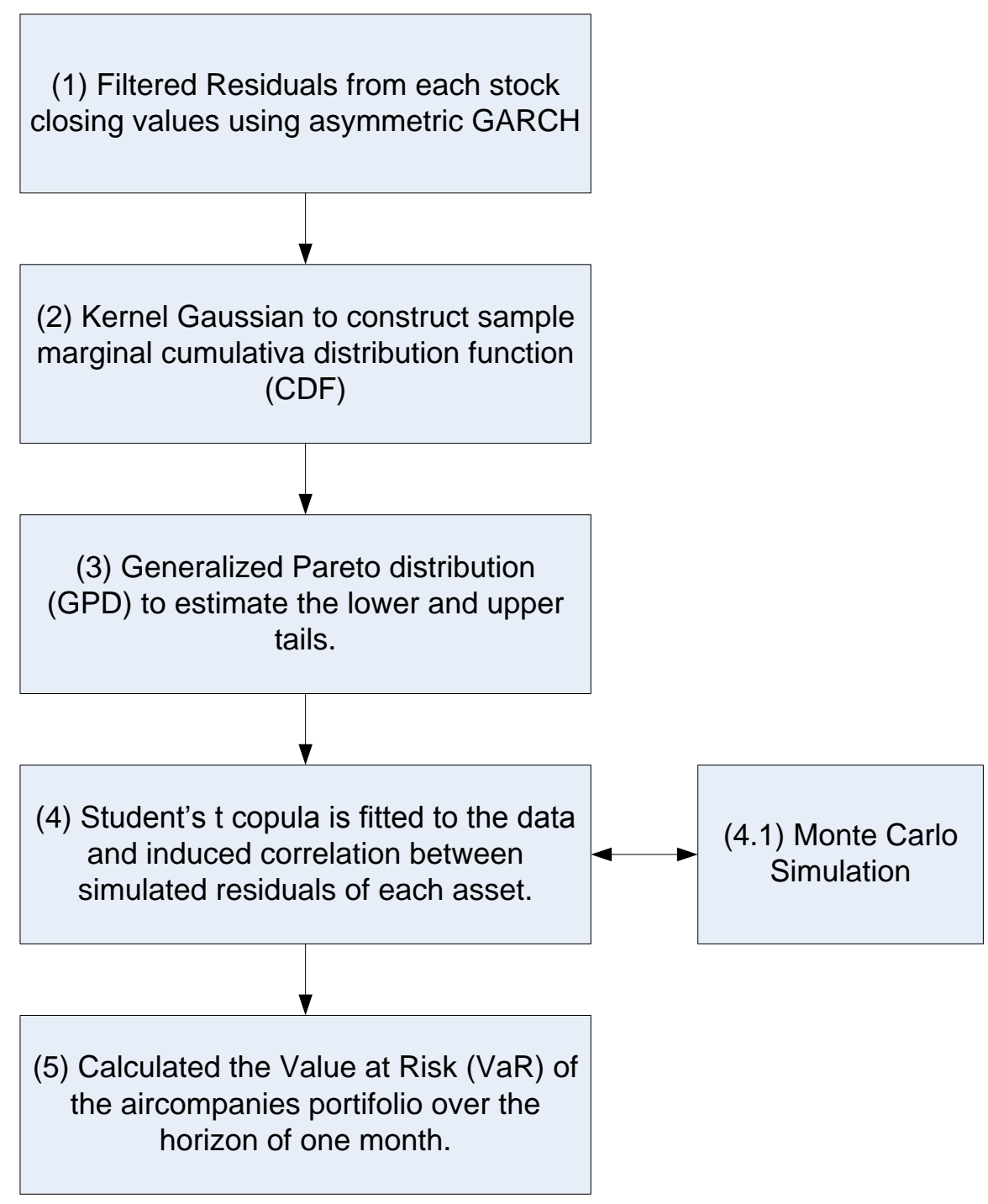

Figure 2. Methodological Framework for Estimation of Risk 
The structure of risk estimation presented in Figure 2 was based on the demonstration of market risk models developed by Mathworks (Mathworks, 2010).

\subsection{Data Selection}

Two portfolios were developed made up of the closing value of the shares of six companies of civil aviation with capital of United States origin and a portfolio of six companies of civil aviation with a capital of European origin. Analyses were performed in both portfolios for the 1310 observations of daily closing share price during the period of 05/03/2007 to 07/12/2012.

Tables 1 and 2 lists the firms used for the formation of the portfolio. An atypical presence of some companies rather than others was observed, this fact can be explained by the composition of arbitrariness in the same period. This means that preference was given in a series of long data enough to be able to include the shock experienced in the financial markets especially in the period between 2008 and 2009. Therefore it was decided not to include companies who had the beginning of its operations after 2007, even in cases of mergers between existing firms.

The source of data was the stock market history values obtained in the Internet. The data selection included only the daily close values which are more suitable to express the stock value in the market.

Table 1 - United States Portfolio Descriptive Statistics

\begin{tabular}{|c|c|c|c|c|c|}
\hline Airline/ Stock code/ Stock Market & Mean & $\begin{array}{c}\text { Standard } \\
\text { Error }\end{array}$ & $\begin{array}{l}\text { Standard } \\
\text { Deviation }\end{array}$ & Minimum & Maximum \\
\hline Delta Air Lines Inc. / (DAL) / NYSE & 10.91 & 0.11 & 3.89 & 3.93 & 21.51 \\
\hline US Airways Group, Inc. / (LCC) / NYSE & 9.88 & 0.22 & 7.8 & 1.76 & 36.15 \\
\hline Southwest Airlines Co. / (LUV) / NYSE & 11.05 & 0.07 & 2.64 & 4.97 & 16.43 \\
\hline United Continental Holdings, Inc. / (UAL) / NYSE & 19.93 & 0.3 & 10.69 & 3.13 & 48.15 \\
\hline SkyWest Inc. / (SKYW) / NasdaqGS & 15.34 & 0.13 & 4.57 & 6.32 & 27.5 \\
\hline American Airlines / (AAMRQ) / OTC Markets & 8.47 & 0.19 & 6.78 & 0.24 & 28.83 \\
\hline
\end{tabular}


Table 2 - European Portfolio Descriptive Statistics

\begin{tabular}{cccccc}
\hline Airline/ Stock code/ Stock Market & Mean & $\begin{array}{c}\text { Standard } \\
\text { Error }\end{array}$ & $\begin{array}{c}\text { Standard } \\
\text { Deviation }\end{array}$ & Minimum Maximum \\
\hline Air Berlin PLC \& Co. Luftverkehrs KG / (AB1.DE) / XETRA & 5.18 & 0.11 & 3.91 & 1.48 & 20.04 \\
Air France-KLM SA / (AF.PA) / Paris & 13.14 & 0.21 & 7.72 & 3.06 & 38.30 \\
easyJet plc / (EZJ.L) / LSE & 396.29 & 2.49 & 90.19 & 220.25 & 700.00 \\
INTL. CONS. AIR GRP / (IAG.L) / LSE & 228.16 & 2.28 & 82.66 & 109.90 & 511.50 \\
Deutsche Lufthansa Aktiengesellschaft / (LHA.DE) / XETRA & 13.34 & 0.10 & 3.60 & 7.86 & 22.45 \\
Ryanair Holdings plc / (RYAAY) / NasdaqGS & 13.34 & 0.10 & 3.60 & 7.86 & 22.45 \\
\hline
\end{tabular}

\section{Application}

\subsection{Estimating Extreme Distributions}

With the standardization of residuals i.i.d. an empirical estimation of the cumulative distribution function (CDF) was performed with a Gaussian kernel. The kernel adjustment aims to derive a smooth curve from a sample to provide the best possible representation of the probability density of the random variable. This represents a way to infer the density from an empirical density function (Alexander, 2008). Hence the CDF sample was softened, but for better estimation of the tails the EVT was used in the residues.

To deal with the estimation of the tails upper and lower thresholds were defined in $10 \%$ of residues. The residues beyond the threshold for each tail were then adjusted using peaks-overthreshold. About the excesses in each tail, the function was negative log-likelihood optimized to estimate the tail index and the scale of the GPD.

\subsection{Estimating the t-Copula}

The copula estimation by likelihood was performed in two steps by the algorithm used implemented in the Matlab function. For (Nystrom and Skoglund, 2002a) the parameters of the degrees of freedom should be specified by the researcher, allowing induce the dependence of tails between assets. The recommendation, however, is that this parameter varies between 1 
and 2 (Nystrom and Skoglund, 2002b). The standardized residuals were transformed into uniform variants by semi-parametric empirical CDF and then adjusted the t-copula to the transformed data. These variants uniform transformed from the CDF for each margin were calibrated by the method of maximum likelihood canonical (CML) (Mathworks, 2012).

\subsection{Portfolio Stimulation Process}

Through the probability function of a random variable is possible to access the probability that an $\mathrm{X}$ value is smaller than $\mathrm{x}$ and access their cumulative distribution function. The uniform variants processed into standardized residuals by inverting the semi-parametric marginal CDF produced the simulated residues consistent with the filtering process AR (1) / GJR (1.1). The simulation was performed with 2000 independent random tests from the residuals of standardized over a period of one month, which rough represent 22 days of trading in financial markets.

\section{Results Analysis}

In this section, we present our findings regarding the risk of loss between the United States and Europe portfolio. The impact of the 2008 crisis in the global economy promoted a serious downturn in the aviation stock market. The transportation sector can be viewed as a mirror of the economic activity. An increase of economic activity, like industrial production and trade relationship rapidly promotes an increase of transportation, with the opposite is also true. The growth of airline transportation is a clear view of economic prosperity with great demand for mobility for business and tourism. An increase of tourism made the air travel for leisure more common activity than could be imagined in few decades ago. The advent of LCC's had an important contribution in this development. Although, the same factors that promoted the growth also poses a great risk for its continuous development. The airlines rely upon the existence of continuous demand of passengers and investments to deal with the strained competition. Other factors, like economic cycles and instability of oil prices are now in the agenda of many airlines strategic planning, making their forecast sketchier. An important point to make is despite the undoubted value of aviation for the whole economy, the industry still isn't able keep the investors settled. This may explain the high variability and risk associated with the airlines stocks. 
Our main interest was the assessment of potential risk of loss between the United States and Europe portfolios. So, we based in the historical share close values is possible to observe the movements in both market and the impact of 2008 crisis. Figures 3 and 4 demonstrate the closing prices of stocks of each airline from the United States and Europe. To perform a comparative analysis within the group of actions, each company had their closing price normalized unitarily; this made the comparison between the assets easier to be visualized due to the different stock values.

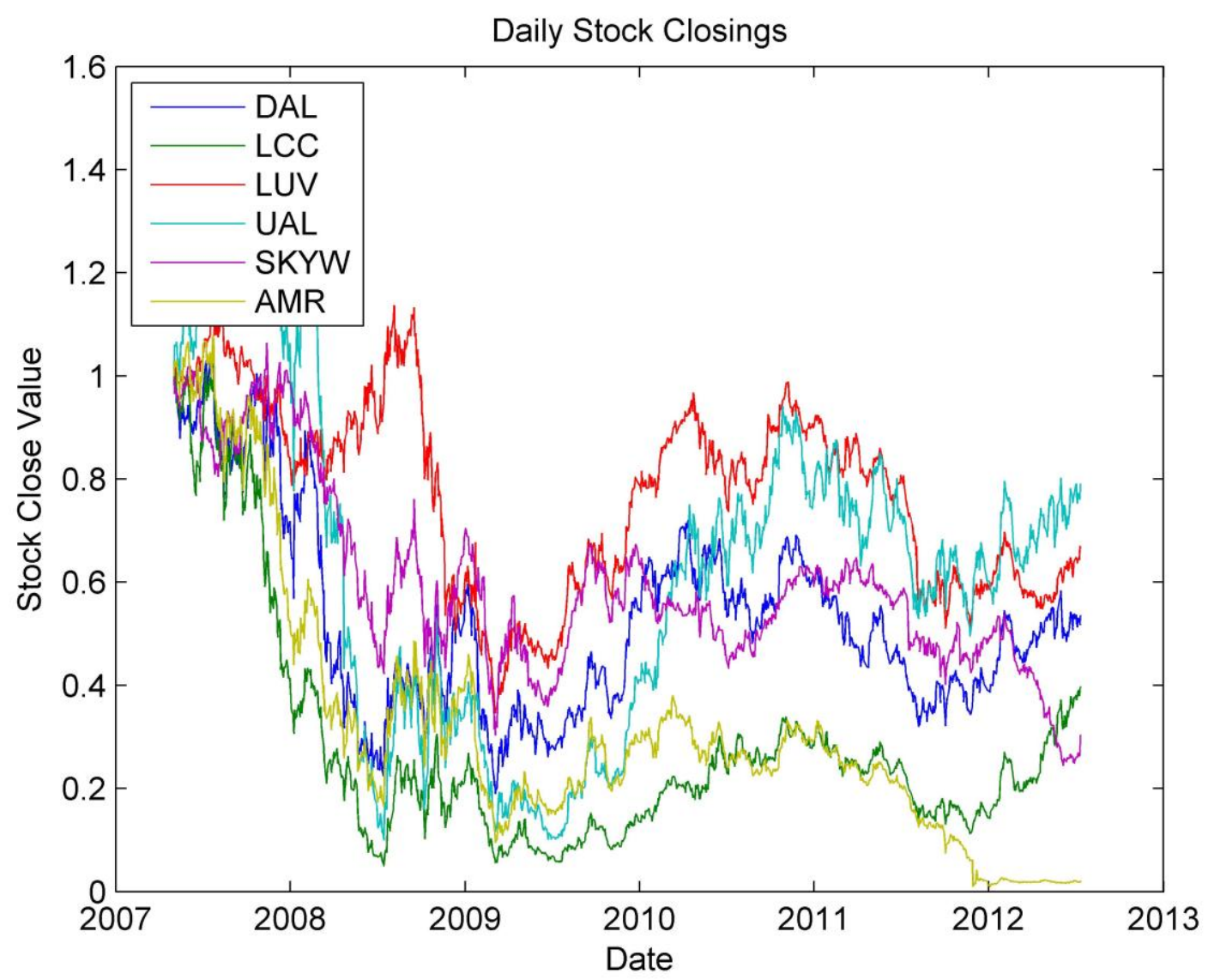

Figure 3 - Historical closing stock price of U.S. airlines. 




Figure 4 - Historical closing stock price of airlines of Europe

Our findings suggest that the Student-t distributions have heavier tails than the normal distribution when $4<D o F \leq 30$ (Rozga and Arneric, 2009). Table 3 presents this fact in both portfolios analyzed in this paper, expressing the adequacy for the fat tail approach. This makes our estimation more suitable to consider the events in the tails. The results simulated are presented in Table 3 in maximum simulated loss and gain and the VaR in confidence intervals. 


\begin{tabular}{lcc}
\hline & US & Europe \\
\hline & & \\
Degrees of Freedom (DoF): & 10.3775 & 16.0124 \\
Maximum Simulated Loss: & $100.19 \%$ & $40.78 \%$ \\
Maximum Simulated Gain: & $72.85 \%$ & $30.59 \%$ \\
Simulated 90\% VaR: & $-19.27 \%$ & $-11.97 \%$ \\
Simulated 95\% VaR: & $-25.79 \%$ & $-15.83 \%$ \\
Simulated 99\% VaR: & $-39.72 \%$ & $-23.55 \%$ \\
\end{tabular}

Following Table 3, the aviation market in the United States and Europe had a prospect of loss when simulated in the model during the analyzed period. This demonstrates that at $95 \%$ the number of shares of companies in the United States would present a maximum loss of $25.79 \%$ and $15.83 \%$ of Europe on the horizon of one month. A difference of $62.91 \%$ higher risk in the portfolio of U.S. companies. Table 3 also presents the values of the $\mathrm{VaR}$ at intervals of $90 \%$ and $99 \%$, where the differences in risk are $61.04 \%$ and $98.71 \%$ respectively, based on the portfolio of European companies.

Despite the economic crisis of 2008 have impacted both the U.S. market and Europe, the effects were greater in the U.S. In a qualitative comparison the IATA Loading Factors (Table 4) show the slow growth of the U.S. market when compared to the European market. We cannot infer a casual effect due the different dimension in the analysis, but in an overview these findings may complement each other. It means that poor growth may be reflected in the stock prices increasing risk of loss through the market perception and reaction. 
Table 4 - IATA Loading Factors ${ }^{1}$

\begin{tabular}{cccccc}
\hline YTD 2009 vs. YTD 2008 & $\begin{array}{c}\text { RPK } \\
\text { Growth }\end{array}$ & $\begin{array}{c}\text { ASK } \\
\text { Growth }\end{array}$ & PLF & $\begin{array}{c}\text { FTK } \\
\text { Growth }\end{array}$ & $\begin{array}{c}\text { AFTK } \\
\text { Growth }\end{array}$ \\
\hline $\begin{array}{c}\text { Europe } \\
\text { North America }\end{array}$ & $-7.6 \%$ & $-4.8 \%$ & 73.5 & $-21.6 \%$ & $-9.4 \%$ \\
$\Delta \%($ North America - Europe $)$ & $-8.9 \%$ & $-5.3 \%$ & 76.6 & $-22.2 \%$ & $-9.9 \%$ \\
& 1.3 & 0.5 & 3.1 & 0.6 & 0.5 \\
\hline
\end{tabular}

The high variability associated with $\mathrm{VaR}$ dealing with the probability of extreme values, like extreme loss, poses a question for the airline industry. Is it possible to give attractive returns over investments? A high volatility sector may have a high cost of capital resulting in poor margins of profit. That means that the expectance of loss in one market can be a bottleneck to attract investment in capital markets.

The aviation industry had a capital investiment of US\$ 680 billion in 2004, from this amount airlines industry alone account for over 55\%, with US\$ 380 billion (IATA, 2006). Despite this past investment, the airline industry is composed by various submarkets with some of them facing structural problems like excess capacity and airport hubs. So, the airlines is a growth industry in a long run with a central role for the economic development, but the expectancy of loss are still to high. The increase of in airline share price in 2010 may be viewed a start point of recover. A point which should be taken into consideration is that the North American and European markets are in different moment of its structure. In a post financial crisis research (Macário and Voorde, 2009) suggests that the European market undergoes a consolidation as the North American market undergoes regeneration (Macário and Voorde, 2009). The differences in the recovery is due in Europe most airlines are being valued by reference to mid-cycle multiple while in United States is the capacity discipline (IATA, 2011).

\footnotetext{
${ }^{1}$ RPK: Revenue Passenger Kilometres measures actual passenger traffic; ASK: Available Seat Kilometres measures available passenger capacity; PLF: Passenger Load Factor is \% of ASKs used. In comparison of 2009 to 2008, PLF indicates point differential between the periods compared; FTK: Freight Tonne Kilometres measures actual freight traffic; AFTK: Available Freight Tonne Kilometres measures available total freight capacity; FLF: Freight Load Factor is \% of AFTKs used; Source: Macário and Voorde (2009).
} 
As expressed before, the impacts of the 2008 crisis promoted a decrease in the pace of economic growth and therefore the transport of cargo and passengers. But, despite the comparable lower variability of the historical portfolio of European companies a future increase in price of petroleum and the recent unresolved problems of European debt raise the expectation of loss in this market. Also important to emphasize is the actual crisis in Europe which lead to a low expectation at net post-tax profits for the industry to fall $62 \%$ in 2012 compared to the last year (\$ 7.9 billion (2011) to $\$ 3$ billion (2012) (IATA, 2012)). This means that just $0.5 \%$ profit of the revenues.

And finally, it is important to mention that like many analytical tools $\mathrm{VaR}$ also has its limitations, such as it is possible to have several losses in a period without changing VaR value. We tried to minimize all potential misinterpretations or misspecification through EVT and Copula to evaluate the VaR. Volatility is associated with the prices up and down, this means the possibility of high profits in a risk market. Despite being a powerful tool for evaluation risk, airlines professionals should rely upon several tools to measure the financial exposure of airlines in the financial market. Our sample was composed of only six companies of each region, the sizes, routes and types of these companies vary. A more intensive research may find different results in a different time frame. This same theoretical and practical approach could be revisited in the future to check the effects of the crisis on the European stock price and therefore the increased risk in the portfolio in both markets.

There are many types of financial risks like, operational, credit and legal risk. In this research we focused only in the market risk due to the potential losses associated to the market overreaction. For further investigations about market risk, a comparative analysis of VaR between the stocks of legacy companies and LLC and between developed and developing airlines markets may be important issues to be analyzed. 


\section{Conclusion}

The main conclusion is that airline industry has high volatility sector in capital market. Market cycles and crises may promote strong variability in airline stock prices with a significant risk of loss and gain. A VaR analysis of two portfolios from of mid-2007 to mid2012 was performed signaling a great expectation of loss in United States compared to Europe. This is probably because of the strong effects of financial crisis in this period. Many factors can account to the variability in the stock market, but airlines industry is in the center of the economic activity following the economic growth and recessions. This means that a market overreaction may have strong influence in the stock prices.

We believe the $\mathrm{VaR}$ is a tool capable to capturing the market perception about an industrial sector. Because of the characteristics of financial data, analysis should be conducted with complementary tools. So, we employed various techniques such as asymmetric GARCH, EVT, Copula and Monte Carlo Simulation to suppress standard limitations regarding the nature of financial data in $\mathrm{VaR}$ evaluation. Our findings of the United States' low performance in this period are consistent with the IATA report on loading factors in the U.S. and Europe during 2008-2009. Despite the different nature of analysis between our research and IATA report, we believe that both can complement each other to show the downturn of United Stated airline stocks due the financial crisis. Limitations in our research like the sample selected and time frame evaluated should be taken in consideration. Capital market is an extreme dynamic sector, so a constant monitoring may benefit the airlines business analysts and researchers. Research on financial aspects of aviation is still limited despite the importance of this industry in the capital market worldwide. Our research tried to render a small contribution for further investigation using a financial analytical tool for economic assessment. 


\section{References}

Air Transport Action Group - ATAG (2012) Facts \& Figures. Retrieved 07/30/2012, from www.atag.org.

Alexander, C. (2008) Quantitative Methods in Finance. New York: John Wiley \& Sons.

Alexander, C. (2009) Market Risk Analysis, Value at Risk Models. New York: John Wiley \& Sons.

Alexander, C. (2010) Practical Financial Econometrics. New York: John Wiley \& Sons.

Bali, T. G. and Neftci, S. N. (2003) Disturbing extremal behavior of spot rate dynamics. Journal of Empirical Finance, vol. 10, n. 4, pp. 455-477.

Bouyé, E., Durrleman, V., Nikeghbali, A., Riboulet, G. and Roncalli, T. (2000) Copulas for finance: A reading guide and some applications. Manuscript, Financial Econometrics Research Center.

Brooks, C., Clare, A., Dalle Molle, J. W. and Persand, G. (2005) A comparison of extreme value theory approaches for determining value at risk. Journal of Empirical Finance, vol. 12, n. 2, pp. 339-352.

Byström, H. N. E. (2005) Extreme value theory and extremely large electricity price changes. International Review of Economics and Finance, vol. 14, n. 1, pp. 41-55.

Delta Airlines (2011) News Release Retrieved 07/30/2012, from news.delta.com

Dempsey, P. S. (1995) Airlines in Turbulence: Strategies for Survival. ransportation Law Journal, vol. 23, n. 15.

Engle, R. F., Ng, V. K. and Rothschild, M. (1990) Asset pricing with a factor-arch covariance structure:: Empirical estimates for treasury bills. Journal of Econometrics, vol. 45, n. 1-2, pp. 213-237.

Fernandez, V. (2005) Risk management under extreme events. International Review of Financial Analysis, vol. 14, n. 2, pp. 113-148.

Fong Chan, K. and Gray, P. (2006) Using extreme value theory to measure value-at-risk for daily electricity spot prices. International Journal of Forecasting, vol. 22, n. 2, pp. 283-300.

Gencay, R. and Selcuk, F. (2004) Extreme value theory and Value-at-Risk: Relative performance in emerging markets. International Journal of Forecasting, vol. 20, n.2, pp. 287-303.

Glosten, L. R., Jagannathan, R. and Runkle, D. E. (1993) On the relation between the expected value and the volatility of the nominal excess return on stocks. Journal of Finance, pp. 1779-1801.

Horta, P., Mendes, C. and Vieira, I. (2010) Contagion effects of the subprime crisis in the European NYSE Euronext markets. Portuguese Economic Journal, vol. 9, n. 2, pp. 115-140.

IATA (2006) Value Chain Profitability IATA Economics Briefing 4. Available at www.iata.org. 
IATA (2011) Airlines - It's All About Choice and Timing Analyst Viewpoint. Available at www.iata.org.

IATA (2012) Profit Risks Skewed to the Downside Financial Forecast. Available at www.iata.org.

Longin, F. M. (1996) The asymptotic distribution of extreme stock market returns. Journal of Business, pp. 383-408.

Macário, R. and Voorde, E. V. d. (2009) The Impact of the Economic Crisis on the EU Air Transport Sector. Policy Department B: Structural and Cohesion Policies, Directore General for Internal Policies.

Mathworks. (2010) Using Extreme Value Theory and Copulas to Evaluate Market Risk, Mathworks.

Mathworks. (2012) Fit copula to data. Statistics Toolbox. Available at www.mathworks.com.

McNeil, A. J. and Frey, R. (2000) Estimation of tail-related risk measures for heteroscedastic financial time series: an extreme value approach. Journal of Empirical Finance, vol. 7, n. 3, pp. 271-300.

McNeil, A. J. and Frey, R. (2000) Estimation of tail-related risk measures for heteroscedastic financial time series: an extreme value approach. Journal of Empirical Finance, vol. 7, n. 3, pp. 271-300.

Minton, B. A. and Schrand, C. (1999) The impact of cash flow volatility on discretionary investment and the costs of debt and equity financing. Journal of Financial Economics, vol. 54, n. 3, pp. 423-460.

Nystrom, K. and Skoglund, J. (2002a) A Framework for Scenario-Based Risk Management. Preprint, Swedbank, Sweden.

Nystrom, K. and Skoglund, J. (2002b) Univariate extreme value theory, garch and measures of risk. Preprint, Swedbank, Sweden.

Pictet, O. V., Dacorogna, M. M. and Müller, U. A. (1998) Hill, bootstrap and jackknife estimators for heavy tails. A practical guide to heavy tails: statistical techniques for analysing heavy tailed distributions, RJ Adler, RE Feldman and MS Taqqu, Eds, pp. 283-310.

Rozga, A. and Arneric, J. (2009) Dependence between volatility persistence, kurtosis and degrees of freedom. Investigación Operacional, vol. 30, n. 1, pp. 32-39.

Southwest Airlines (2011) Southwest Airlines Reports. Retrieved 07/30/2012, from www.southwestonereport.com/2010. 